\title{
Akupunktur in der palliativen Krebsbehandlung?
}

\section{Taugt die Akupunktur zur palliativen Krebsbehandlung? Diese Frage sollte ein systematisches Review aller Stu- dien zu diesem Thema beantworten.}

- Insgesamt fanden die Autoren $41 \mathrm{Stu}$ dien $\mathrm{zu}$ folgenden Indikationen: Schmerz, Übelkeit, Hitzewallungen, Müdigkeit, Xerostoma, postoperativer Ileus, Angst und Schlafstörungen. Bei weitem die meisten Studien beschäftigten sich mit Chemotherapie-bedingter Übelkeit; viele davon waren jedoch von methodisch fragwürdiger Qualität.

$\mathrm{Zu}$ den anderen Symptomen von Krebskranken gab es deutlich weniger Studien, die zudem häufig methodisch angreifbar waren. Die Autoren kommen dementsprechend zu einem ernüchternden Schluss: Bei Übelkeit ist die Datenlage positiv, aber letztlich nicht völlig überzeugend. Bei allen anderen Symptomen von Krebspatienten ist die palliative Wirksamkeit der Akupunktur nicht belegt.

\section{Kommentar}

In den vielen Krebsambulanzen wird die Akupunktur heute als ein Standard-Palliativum für die meisten Beschwerden von Krebspatienten eingesetzt. Die vorliegende, sehr gut gemachte Analyse zeigt, dass dieses Vorgehen mehr auf Glauben als auf Evidenz beruht. Krebspatienten nehmen ganz offenbar diese Therapieform sehr gut an, vielleicht nicht zuletzt weil sie so gut wie keine ernsten Nebenwirkungen hat. Als kritische Ärzte sollten wir uns dennoch fragen, inwieweit die Beliebtheit und der scheinbare Nutzen der Akupunktur auf der Erwartungshaltung der Patienten und inwieweit auf belegbarer Effektivität beruhen. Einige werden sicher einwenden, dass dies einerlei sei - Hauptsache es hilft! Wer heilt hat Recht! Dem würde ich entgegenhalten, dass wir uns mit dieser Einstellung den Zugang zu der jeweils effektivsten Therapie erschweren - und das kann doch sicher nicht im Interesse der Patienten sei.

E. ERNST :

- M. K. Garcia et al.

Systematic review of acupuncture in cancer care: a synthesis of the evidence. J. Clin. Oncol. 2013 Mar 1;31(7):952-60. doi: 10.1200/ JCO.2012.43.5818

\section{ACE-Hemmer und ARBs: Nephroprotektion trotz Kreatininanstieg}

Bei Patienten mit Niereninsuffizienz kann eine deutliche Erhöhung des Kreatinins unter der Behandlung mit ACE-Hemmern und $\mathrm{AT}_{1}$-Rezeptorblokern (ARB) toleriert werden.

- Retrospektiv wurde der Verlauf von 48 Patienten - darunter 30 Diabetiker - mit einem Serumkreatinin über $1,4 \mathrm{mg} / \mathrm{dl}$ oder einer Proteinurie über $1 \mathrm{~g} / \mathrm{d}$ mindestens 3,5 Jahre beobachtet. Zur Blutdrucksenkung und Nephroprotektion wurden ACE-Hemmer (bei 79\% der Patienten), $\mathrm{AT}_{1}$-Rezeptorblocker (56\%), deren Kombination (35\%), Aldosteronantagonisten (25\%) und Furosemid (83\%) verordnet.

Die Nierenfunktion nahm während der sechsjährigen Beobachtungsdauer nur um $1,61 \mathrm{ml} / \mathrm{min} / 1,74 \mathrm{~m}^{2}$ pro Jahr ab. Der Kreatininanstieg betrug bei $41 \%$ der Patienten mehr als 30\% (im Mittel 58\%) des Ausgangswertes. Die Behandlung war bei Patienten mit weniger als $30 \%$ und mehr als 30\% Kreatininanstieg

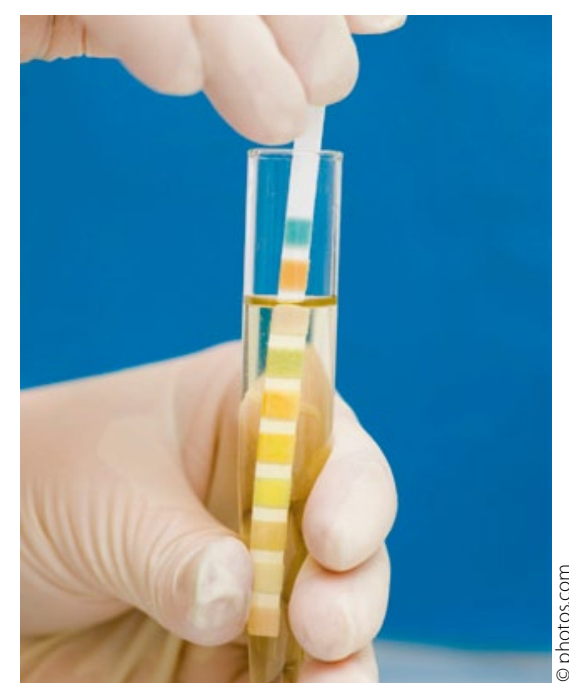

Abnahme der Nierenfunktion lässt sich bremsen.

gleichermaßen erfolgreich. Während sechs Jahren gab es nur drei therapiebedingte Hospitalisierungen. Im Vergleich mit anderen Studien sind auch zwölf Fälle von Dialysepflichtigkeit bzw. Tod als gering zu bewerten.

\section{Kommentar}

Die Hemmstoffe des Renin-Angiotensin-Systems senken bei Patienten mit Nephropathie zuverlässig den Blutdruck, verhindern bzw. verlangsamen die Progression der Nierenerkrankung und verlängern den Zeitraum bis zur Dialysepflichtigkeit. Doch weil sie das Serumkreatinin und-kalium erhöhen können, werden sie häufig nur sehr zurückhaltend eingesetzt oder gar vermieden. In dieser Studie wurden ACE-Hemmer und ARBs auch bei größeren Anstiegen nicht abgesetzt. Dieses Konzept scheint erfolgreich zu sein. Es bringt eine sehr gute Einstellung des systolischen Blutdrucks, eine langsame Progression der Nierenfunktionsverschlechterung und eine geringe Rate therapieassoziierter schwerer Nebenwirkungen. Nur bei anhaltender Hyperkaliämie oder symptomatischer Hypotonie wurde die Dosis reduziert oder die Therapie beendet.

H. HolzGREVE =

\section{- S. Hirsch et al.}

Tolerating increases in the serum creatinine following aggressive treatment of chronic kidney disease, hypertension and proteinuria: pre-renal success. Am. J. Neprhol. 36 (2012) 430- 437 